\title{
"Watch Me!" Training Increases Knowledge and Impacts Attitudes Related to Developmental Monitoring and Referral Among Childcare Providers
}

\section{Gail Chödrön,}

Email chodron@wisc.edu

Brian Barger,

Kris Pizur-Barnekow,

Stephan Viehweg,

Alexandra Puk-Ament,

This is the author's manuscript of the work published in final form as:

Chödrön, G., Barger, B., Pizur-Barnekow, K., Viehweg, S., \& Puk-Ament, A. (2020). "Watch Me!” Training Increases Knowledge and Impacts Attitudes Related to Developmental Monitoring and Referral Among Childcare Providers. Maternal and Child Health Journal. 
Waisman Center University Center for Excellence in Developmental

Disabilities, University of Wisconsin-Madison, 1500 Highland

Avenue, Madison, WI, 53705 USA

School of Public Health, Georgia State University, Atlanta, GA, USA

Department of Occupational Science and Technology, University of WisconsinMilwaukee, Milwaukee, WI, USA

Riley Child Development Center, Indiana University, Bloomington, IN, USA

Children's Hospital Colorado, University of Colorado Anschutz Medical Campus, Aurora, USA

\section{Abstract \\ Objectives}

To evaluate the impact of "Watch Me!" developmental monitoring training on childcare providers' knowledge and attitudes related to monitoring developmental milestones and making recommended referrals when there is a concern about a child's development.

\section{Methods}

A pretest-posttest design using web-based surveys was used to assess the impact of "Watch Me!" training on knowledge and attitudes related to conducting five key components of developmental monitoring (tracking development, recognizing delays, talking to parents about development, talking to parents about concerns, and making referrals). Variables included belief that developmental monitoring is important and is part of childcare provider role; perceived knowledge of, and-access to tools for, and prioritization of 
developmental monitoring; and ability to list recommended referrals when there is a concern.

\section{Results}

Childcare providers demonstrated a significant pre-post increase in perceived knowledge and access to the tools to engage in five core components of developmental monitoring after completing "Watch Me!" training. There was also a significant pre-post increase in childcare providers' ability to list the child's doctor as an appropriate referral (39 pre-63\% post), but not in the ability to list Part C/Part B programs as an appropriate referral (56 pre-58\% post).

\section{Conclusions for Practice}

"Watch Me!" training may be effective at impacting targeted areas of knowledge and attitude about developmental monitoring among childcare providers in the short term.

\section{Keywords}

Child care

Developmental monitoring "learn the signs. act early."

Early identification

Early intervention

\section{Electronic supplementary material}

The online version of this article (https://doi.org/10.1007/s10995-020-03097-w) contains supplementary material, which is available to authorized users.

\section{Significance}

"What is already known about this subject?" 
Universal developmental monitoring and screening are effective at identifying children at risk for developmental disability. However, many children are not screened. Developmental monitoring and screening practice varies widely in childcare settings. Some childcare providers report not perceiving universal developmental monitoring, screening, and referral to be part of their role.

"What this study adds"

Completing online "Watch Me!" training impacts knowledge and attitudes related to conducting developmental monitoring and referral among childcare providers.

\section{Introduction}

Approximately $15 \%$ of children have a developmental disability of any type ${ }^{1}$ (Boyle et al. 2011). Although there is general agreement that early intervention can impact child and family outcomes (Bradshaw et al. 2015; Landa and Kalb 2012; Rogers et al. 2012, 2019), the majority of children who might benefit are not identified, let alone served, before entering kindergarten (Guevera et al. 2013; Interagency Autism Coordinating Committee 2017; Macy et al. 2014). Universal developmental monitoring and screening is an important step in promoting access to developmental evaluation and intervention (Hagan et al. 2017). Developmental monitoring refers to observing how a child meets typical developmental milestones, recognizing when milestones are not being reached, and talking about concerns (Developmental Monitoring and Screening n.d.; Hagan et al. 2017, p. 78). Developmental screening refers to the use of a standardized, norm-referenced tool validated to ascertain risk for developmental disability (Hagan et al. 2017, p. 78).

Despite guidance for universal developmental monitoring and screening practice in primary care settings (Hagan et al. 2017), only about a third of children 935 months of age receive developmental screening from a health care provider, and only $37 \%$ receive developmental monitoring (Hirai et al. 2018). This low rate of developmental monitoring and screening in health care points to the importance of engaging a broader set of professionals in early detection efforts. Communitybased professionals who work with families of young children can play an 
important role in the early identification and referral of children at risk for a developmental disability (Council on Children with Disabilities 2006; PizurBarnekow et al. 2010). However, programmatic requirements to conduct developmental monitoring and screening are not the norm in early care and education (Head Start/Early Head Start programs are a notable exception), though standards and requirements for early identification practice are included in some voluntary accreditation programs in order to achieve accreditation and in some states' Quality Rating and Improvement Systems (QRIS) to achieve higher QRIS rating levels. The National Association for the Education of Young Children (NAEYC) professional preparation standards (2009, pp. 13-14) do include using observation and validated tools to identify children with disabilities, and NAEYC identifies developmental screening as best practice for all childcare programs (National Association for the Education of Young Children 2018). Further, identifying children from birth through age 21 who are eligible to receive services through Part C/Part B services is mandated through federal Child Find regulations (34 CFR 303.302, 20 U.S.C. 1412(a)(3)). Nonetheless, despite NAEYC professional preparation standards and Child Find mandates, neither prescribes specific developmental monitoring and screening practices, and early detection processes are known to vary widely (Bartlett and Mickelson 2019; Bricker et al. 2013; Macy et al. 2014).

Data on the current practice of developmental monitoring, screening and referral in childcare settings is limited. However, there is literature on childcare providers' knowledge and attitudes that suggests these professionals may not see it as their role to monitor and screen all children for the purposes of identifying risk for developmental disability and referring for services, regardless of NAEYC recommendations (Boh and Johnson 2018; Branson et al. 2009; Branson and Bingham 2017; Burt 2013; Chödrön et al. 2019). Given the lack of uniform guidance or requirements for developmental monitoring and screening in the childare profession, these research findings suggest that changing childcare provider practice will require training that can effectively change relevant knowledge and attitudes.

To support developmental monitoring across early childhood settings, the Centers 
for Disease Control and Prevention (CDC) developed the Learn the Signs. Act Early. public health communications campaign, which provides parent education materials in print, online, and mobile app formats and training resources specifically designed for early childhood professionals. Among those childcare providers and programs unable or unwilling to conduct developmental screening, developmental monitoring may be a readily adopted practice that can foster early identification of risk for developmental disability and access to early intervention (Branson et al. 2008). When developmental monitoring leads to concern about a child's development, a referral can be made to child's doctor for developmental screening. Therefore, community-based professionals who conduct only developmental monitoring can still play a role in increasing access to developmental screening. Training specifically designed to increase knowledge and shape attitudes about developmental monitoring among childcare providers is provided through the CDC's "Watch Me! Celebrating Milestones and Sharing Concerns" training modules (Raspa et al. 2015). "Watch Me!" is comprised of four online modules on developmental monitoring providing one hour of free continuing education credit (https://www.cdc.gov/ncbddd/watchmetraining/index.html). The modules describe developmental monitoring and address: why developmental monitoring is important, the role of childcare providers in developmental monitoring, how to monitor development, and how to talk to parents about developmental milestones and concerns. Although the acceptability and impact of Learn the Signs. Act Early. parent education materials has been completed (Burt 2013; Graybill et al. 2016; Raspa et al. 2015), there was a need to study the impact of Watch Me! training on childcare providers' knowledge and attitudes related to developmental monitoring.

\section{Methods}

\section{Study Design}

The impact of "Watch Me!" training on knowledge and attitudes among childcare providers was assessed as part of a larger program evaluation study of the acceptability, feasibility, and effectiveness of developmental monitoring using LTSAE resources in childcare settings. Based on the University of WisconsinMadison (UNIVERSTTY blinded) Institutional Review Board (IRB) Office's 
QI/Program Evaluation Self-Certification Tool and a follow-up discussion with Education and Social/Behavioral Science IRB staff, this study did not constitute research as defined under 45 CFR 46.102(d) and IRB review was not required. The "Framework for Program Evaluation in Public Health" (Centers for Disease Control and Prevention 1999) was utilized to guide overall program implementation and evaluation design, which included prioritizing key stakeholder input into program design and meaningful outcome measures. Based on this input, evaluation of the "Watch Me!" modules was undertaken in two study arms that reflect the ways childcare professionals pursue training: (1) individual training based on personal interest with no implementation support offered (Training-only), and (2) program-wide training and implementation with technical assistance (Training + TA). Training-only and Training + TA groups differed in recruitment strategy, and a later phase of implementation and related data collection conducted only for the Training + TA group. Procedures for access to and evaluation of training were the same in both study arms. Participants, regardless of study arm, were provided access to a website with links to the web-based pre-test, training, and post-test. The website allowed access to the training without completing the pre-test, for individuals who declined to participate in the study. Upon completion of the pre-test, participants were redirected to the "Watch Me!" training. Participants were directed to complete the post-test after finishing the online training, but were able to decline participation.

\section{Sample}

The analytical sample combines childcare providers completing individual training (Training-only) and childcare providers completing training as part of programwide implementation (Training + TA). In the Training + TA study arm, a purposeful sampling strategy was used to recruit childcare programs for program-wide implementation to ensure participation of programs representing the following predetermined important criteria: geographic diversity (i.e., rural, suburban/urban, and dense urban core); center- and home-based; regulated and unregulated; national accreditation status; and QRIS participation and rating level. This strategy was successful at including programs by geography, program type, QRIS rating levels, and national accreditation status (Table 1). In the Training-only study arm, 
a self-selection recruitment strategy was used. Access to the training was advertised through national, regional, and state early childhood email distribution lists that are routinely used for advertising educational opportunities to childcare providers, and participation was open to all respondents who self-identified as childcare providers and had internet access in the U.S. Pre- and post-training survey data were collected from August, 2015 through May, 2016. Completed preand post-surveys were matched by a unique respondent identifier. Findings are reported for 127 matched pre-post surveys, 59.1\% of which are from the Trainingonly study arm and $40.9 \%$ are from the Training + TA study arm (Table 2).

\section{Table 1}

Distribution of programs participating in training + TA by pre-determined criteria

\begin{tabular}{|c|c|c|c|c|c|}
\hline Program type & $\begin{array}{l}\text { Rural } \\
(\mathrm{n}= \\
6)\end{array}$ & $\begin{array}{l}\text { Urban/suburban } \\
(\mathrm{n}=5)\end{array}$ & $\begin{array}{l}\text { Dense } \\
\text { urban (n } \\
=7)\end{array}$ & $\begin{array}{l}\text { Nationally } \\
\text { accredited }\end{array}$ & $\begin{array}{l}\text { QRIS }^{a} \\
\text { Rating }\end{array}$ \\
\hline \multirow[t]{3}{*}{$\begin{array}{l}\text { Regulated } \\
\text { center }(\mathrm{n}=10)\end{array}$} & 3 & 4 & 3 & Yes, $n=4$ & $\begin{array}{l}5 \text { out of } \\
5, \mathrm{n}=6\end{array}$ \\
\hline & & & & No, $n=6$ & $\begin{array}{l}4 \text { out of } \\
5, \mathrm{n}=1\end{array}$ \\
\hline & & & & & $\begin{array}{l}3 \text { out of } \\
5, \mathrm{n}=3\end{array}$ \\
\hline \multirow[t]{2}{*}{$\begin{array}{l}\text { Regulated home } \\
(\mathrm{n}=4)\end{array}$} & 2 & $0^{\mathrm{b}}$ & 2 & Yes, $n=1$ & $\begin{array}{l}5 \text { out of } \\
5, \mathrm{n}=2\end{array}$ \\
\hline & & & & No, $n=3$ & $\begin{array}{l}2 \text { out of } \\
5, \mathrm{n}=2\end{array}$ \\
\hline \multirow[t]{3}{*}{$\begin{array}{l}\text { Unregulated } \\
\text { center }(n=4)\end{array}$} & 1 & 1 & 2 & Yes, $\mathrm{n}=0$ & $\begin{array}{l}3 \text { out of } \\
4, \mathrm{n}=1\end{array}$ \\
\hline & & & & No, $n=4$ & $\begin{array}{l}1 \text { out of } \\
4, \mathrm{n}=1\end{array}$ \\
\hline & & & & & $\begin{array}{l}\text { NA, } \mathrm{n} \\
=2\end{array}$ \\
\hline \multicolumn{6}{|c|}{${ }^{\mathrm{a}} Q R I S$ quality rating and improvement system } \\
\hline \multicolumn{6}{|c|}{$\begin{array}{l}{ }^{\mathrm{b}} \text { One urban/suburban regulated home-based childcare program was recruited but } \\
\text { withdrew soon after study initiation }\end{array}$} \\
\hline
\end{tabular}




\section{Table 2}

Participants in analytic sample by study arm and type of program

\begin{tabular}{|c|c|c|c|}
\hline Program type & $\begin{array}{l}\text { Training-only } \\
\text { (\% of total) }\end{array}$ & $\begin{array}{l}\text { Training + TA } \\
\text { (\% of total) }\end{array}$ & $\begin{array}{l}\text { Total } \\
\text { (\% of total) }\end{array}$ \\
\hline $\mathrm{HS} / \mathrm{EHS}^{\mathrm{a}}$ & 10 & 0 & $10(7.9)$ \\
\hline Regulated center & 39 & 41 & $80(62.9)$ \\
\hline Regulated home & 16 & 5 & $21(16.5)$ \\
\hline Unregulated center & 0 & 5 & $5(3.9)$ \\
\hline Other/unknown & 10 & 1 & $11(8.7)$ \\
\hline Total & $75(59.1)$ & $52(40.9)$ & 127 \\
\hline
\end{tabular}

\section{Measures}

Measures of knowledge and attitudes were collected through a survey instrument designed by the project evaluation team in collaboration with the study sponsor (i.e., CDC Act Early team). The survey instrument was designed to evaluate perceived knowledge, demonstrated knowledge (i.e., ability to list information), and attitudes related to developmental monitoring specifically targeted in "Watch Me!" training. The primary role of the CDC team was to provide guidance related to the variables the training was designed to impact. The study team designed a survey instrument to measure change in these variables. A CDC survey design expert was consulted to refine final measures. In alignment with training content, developmental monitoring was conceptualized as being comprised of five components:

Tracking development: "Tracking the whole development of each child in your care";

Recognizing when development does not match the age norm: 
"Recognizing when a domain of a child's development does not match what is typical for children of that age";

Talking to parents about development: "Talking with each child's parents about the whole development of their child";

Talking to parents about concerns: "Talking to parents when you have a concern about how their child is developing";

Making referrals: "Connecting parents to outside programs or resources that can help when there is a concern about how their child is developing".

For each of five components of developmental monitoring (i.e., tracking development; recognizing when development does not match the age norm; talking to parents about development; talking to parents about concerns; and making referrals), perceived knowledge and access to tools, and prioritization, were assessed using a continuous sliding scale that was converted to a 100 -point numeric scale in response to the following statements:

Perceived knowledge: "I have the knowledge and skills I need to do this effectively";

Access to tools: "I have the tools I need to do this effectively";

Priority: "This should be a top priority for early care and education professionals at my center".

Demonstrated knowledge of referral was measured by asking respondents to list where they could refer a child if they were concerned about any aspect of their development. Attitudes about components of developmental monitoring were further measured through the questions 'Do you believe it is important to keep track of the whole development of every child in your care using an objective checklist or questionnaire?', and 'Do you see it as part of your role to suggest that parents talk to their child's doctor when there is a concern about how their child is developing?'. 


\section{Data Analysis}

Narrative responses to the demonstrated knowledge of referral measure were coded to the categories of Part C/Part B, doctor, other, and unknown by two members of the study team using a consensus coding strategy. All data were cleaned and analyzed within the $\mathrm{R}$ statistical environment. The psych package was used to develop descriptive statistics, and the base and MASS packages were used to determine the distributions for outcome variables (Revelle and Revelle 2015). Generalized linear mixed (GLM) models with pre-post responses nested in participants were developed and considered using functions from the nlme and lme4 packages; final analyses were conducted with the $\operatorname{glmm} P Q L$ function available in the MASS package requiring GLM inputs from the nlme package (Bates et al. 2015; Pinheiro et al. 2018; Ripley et al. 2013). Poisson distributions best captured the residuals of most continuous pre-post outcomes except for the Priority of Tracking in the Tracks Development of All Children for which QuasiPoisson analyses accounting for over-dispersion were selected. Pre-post binary outcomes were analyzed with GLM quasibinomial logistic regression.

\section{Results}

Median and 95\% confidence interval for continuous data are available in Figs. 1, 2, 3, 4, 5 and proportion data are available in Fig. 6 for binary comparisons; numeric details of descriptive data including sample sizes, means, medians, standard deviations, and proportions are available in Online Supplemental Tables.

\section{Fig. 1}

Pre to post change in knowledge, access to tools, and prioritization of tracking children's development among childcare providers in response to the "Watch Me!" training. $* * * p<=.001$ 


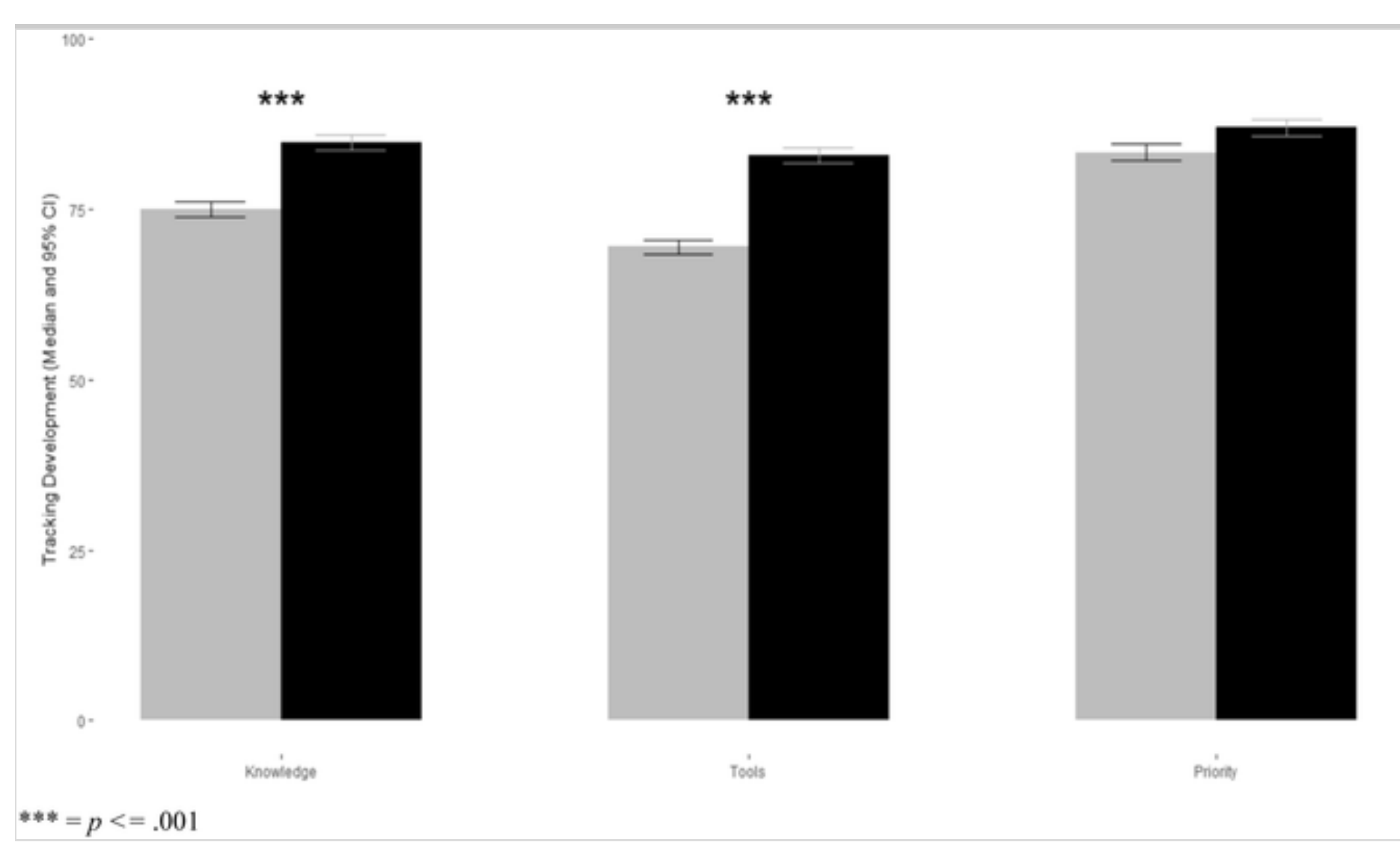

Fig. 2

Pre to post change in knowledge, access to tools, and prioritization of recognizing developmental delay among childcare providers in response to the "Watch Me!" training. $* * * p<=.001$ 


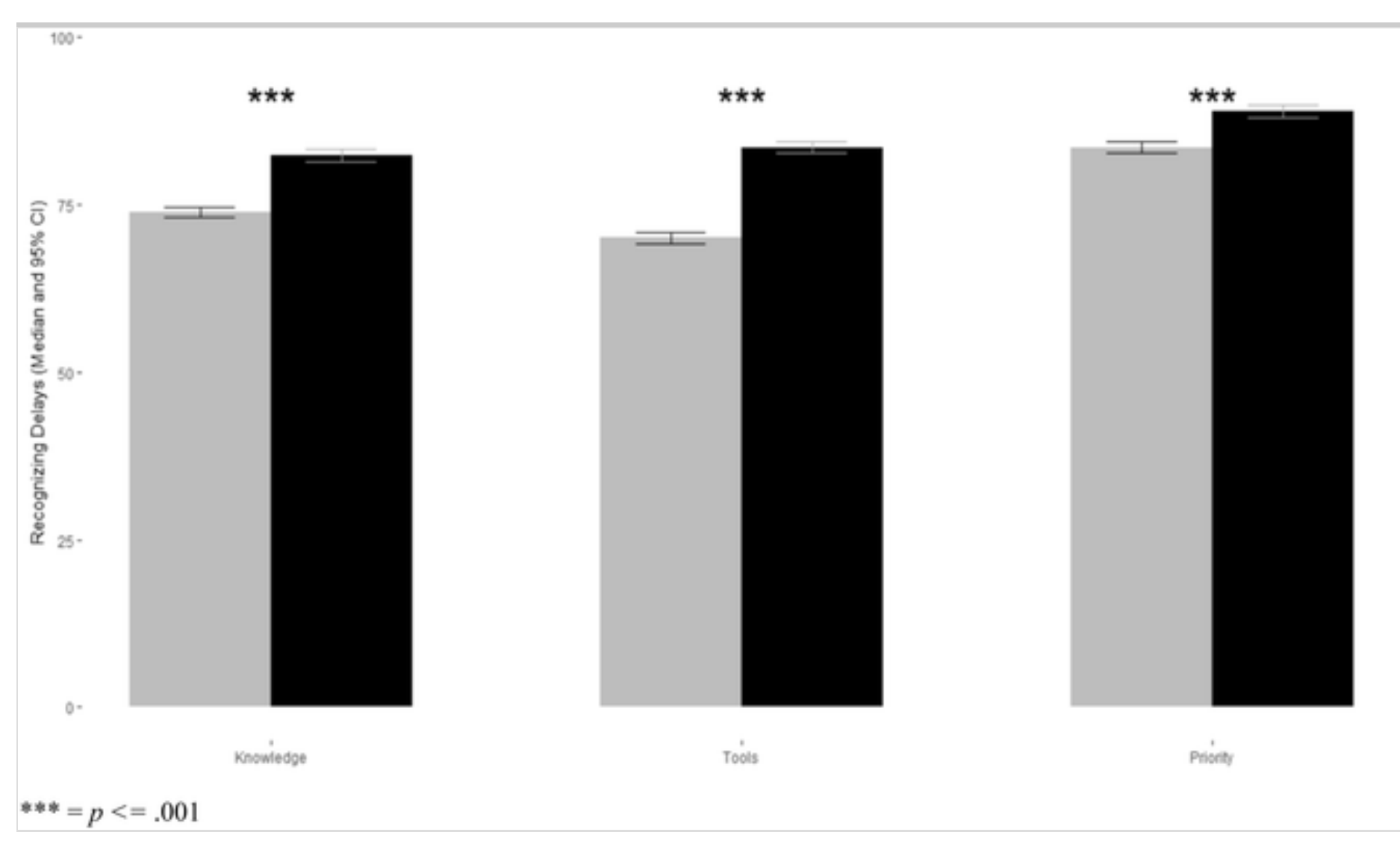

Fig. 3

Pre to post change in knowledge, access to tools, and prioritization of talking to parents about child development among childcare providers in response to the "Watch Me!" training. *** $p<=.001$ 


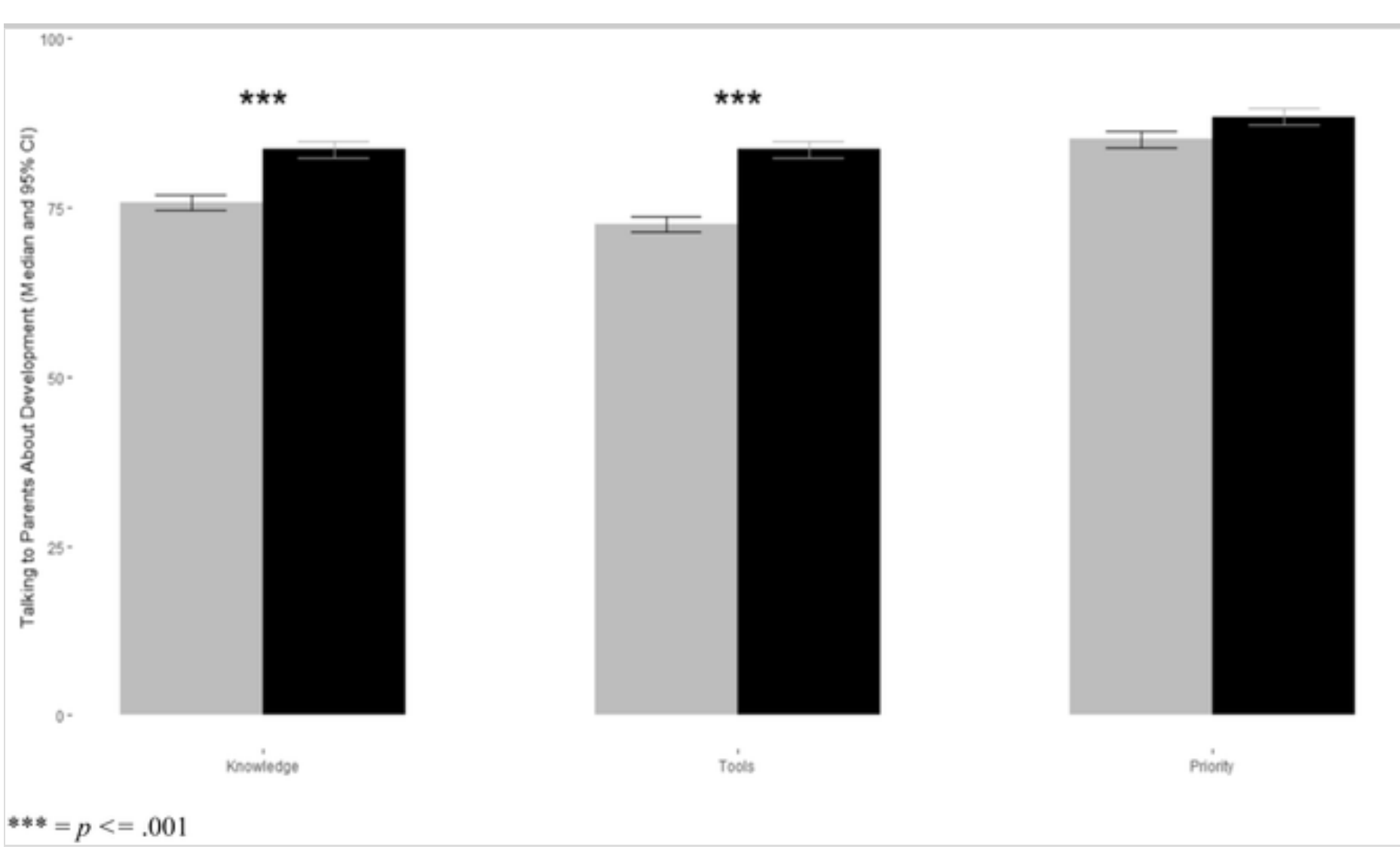

Fig. 4

Pre to post change in knowledge, access to tools, and prioritization of talking to parents when there is a developmental concern among childcare providers in response to the "Watch Me!" training. *** $p<=.001$ 


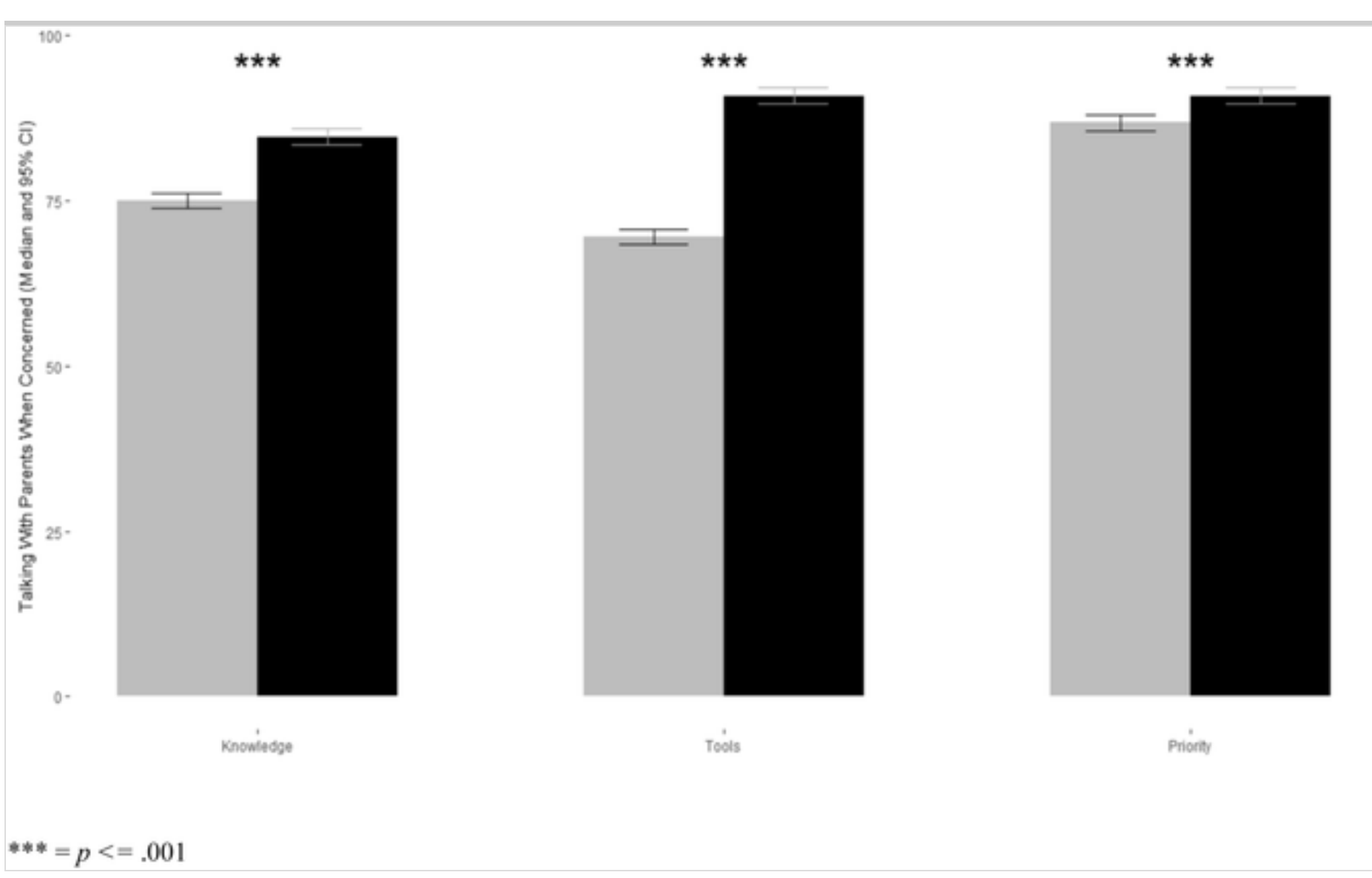

\section{Fig. 5}

Pre to post change in knowledge, access to tools, and prioritization of making referrals when there is a developmental concern among childcare providers in response to the "Watch Me!" training. *** $p<=.001$ 


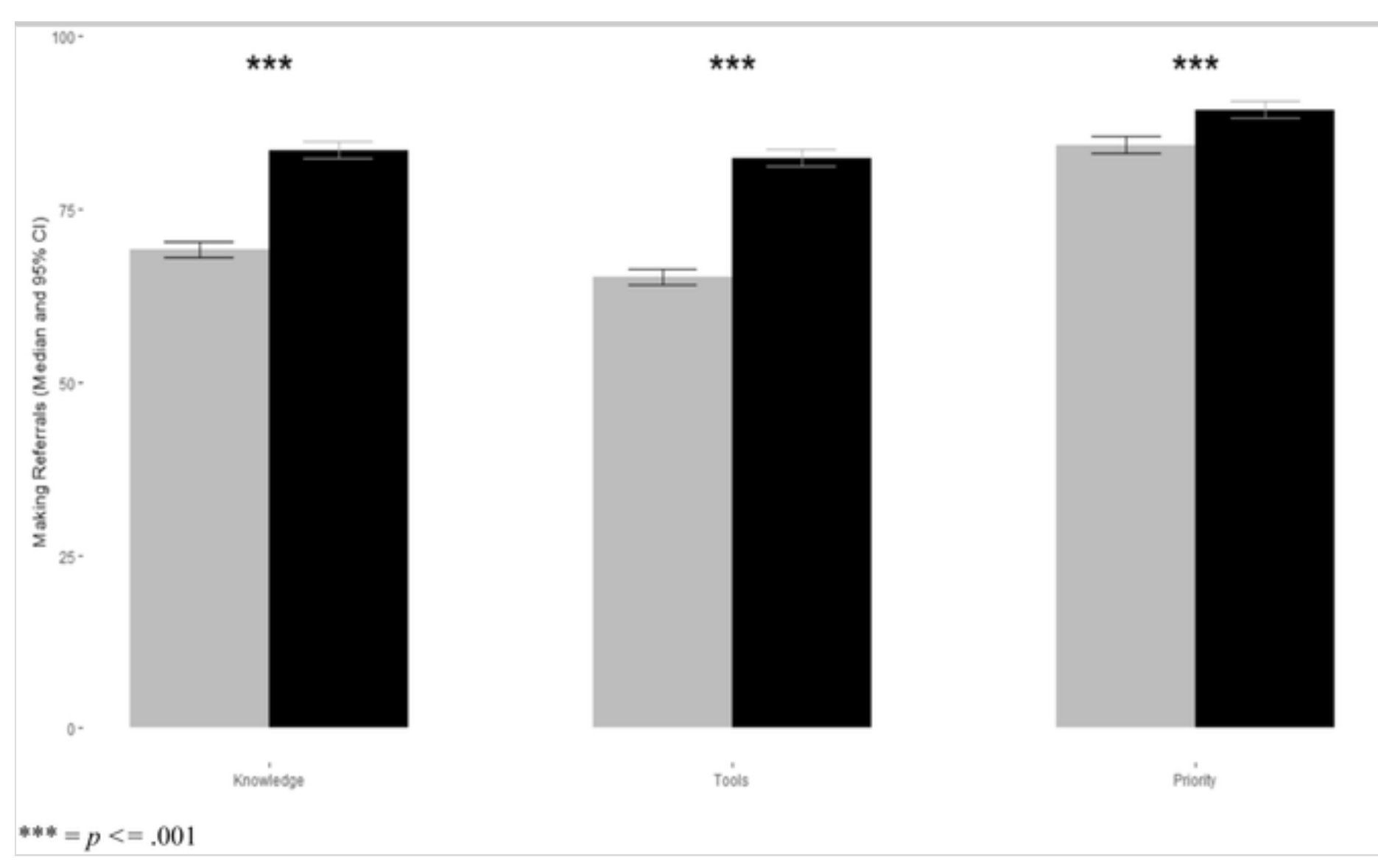

Fig. 6

Pre to post change in childcare providers indicating belief that developmental monitoring is important and demonstrating knowledge of referral to part $\mathrm{c} / \mathrm{part} \mathrm{b}$ and to the child's doctor. ${ }^{* * *} p<=.001$ 


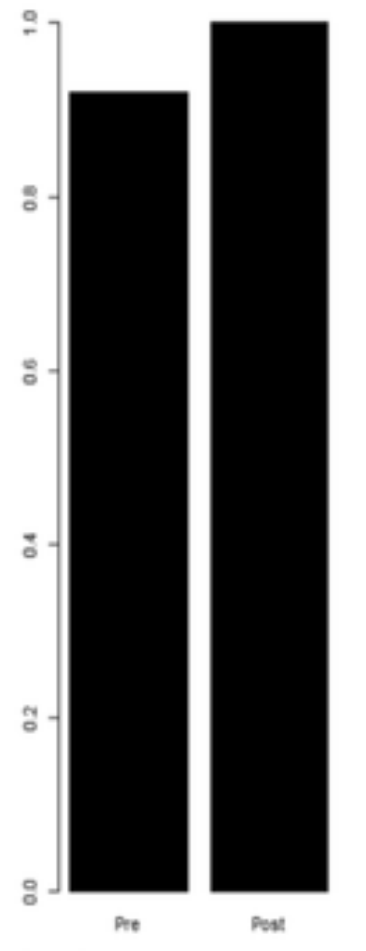

Stasing Develepmental Ulontoring is impertant
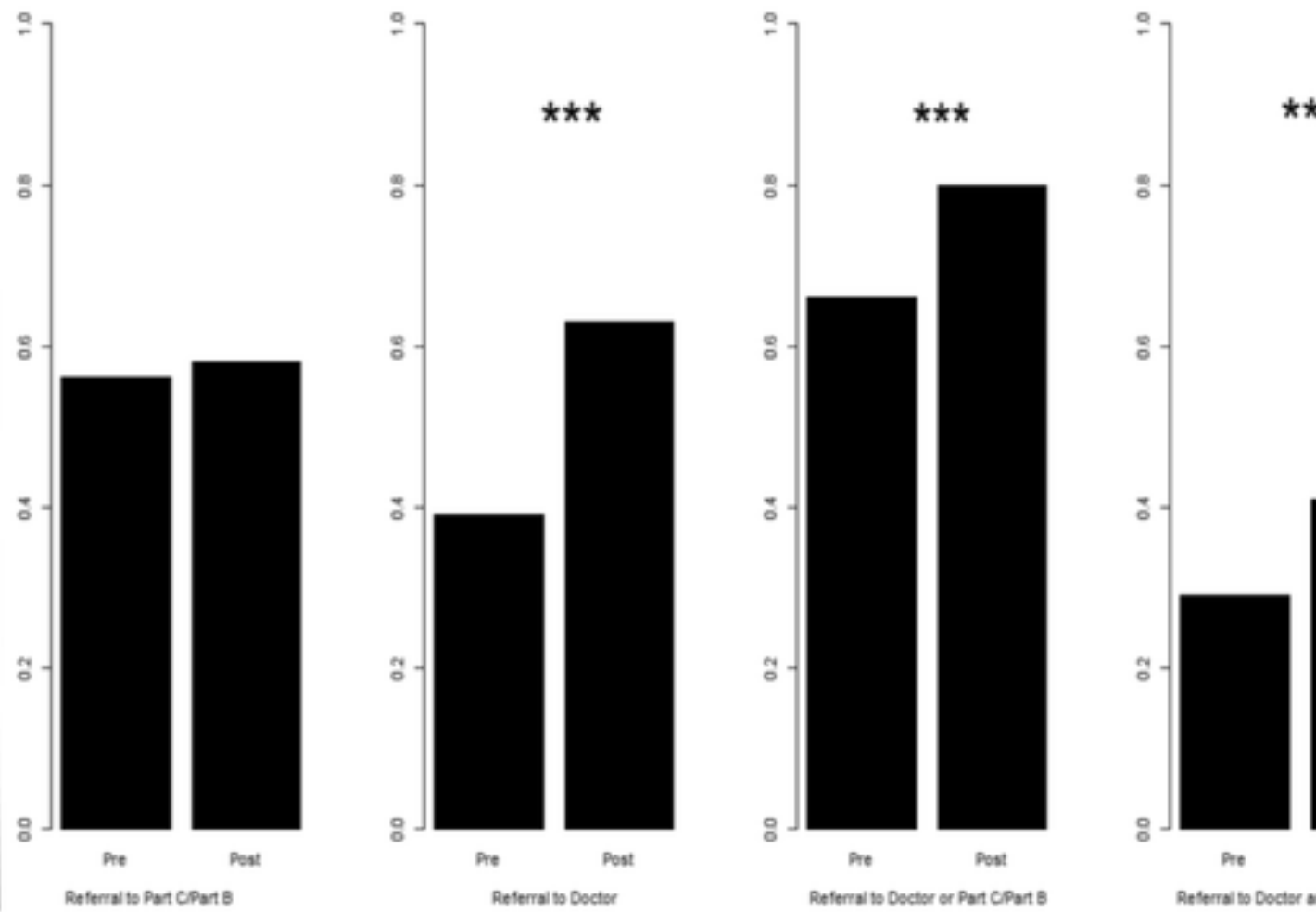

Pre

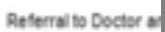

$* * *=p<=.001$

Tracking development. There was a statistically significant ${ }^{2}$ pre-post increase in perceived knowledge $(\operatorname{pre}=81.5 ;$ post $=91.5 ; \beta=0.12, t[121]=4.32, p<0.001)$ and access to tools (pre $=72$; post $=88 ; \beta=0.18, t[121]=5.91, p<0.001$ ) (Fig. 1; Table 3).

\section{Table 3}

Pre-post effect of watch Me! training on perceived knowledge, access to tools and priori variables

\begin{tabular}{|l|l|l|l|l|l|l|l|l|l|l|l|}
\hline & B & Perceived knowledge & \multicolumn{3}{|c|}{ Perceived access to tools } & \multicolumn{2}{|c|}{ Priority } \\
\hline & SE & $\begin{array}{l}\text { t } \\
\text { value }\end{array}$ & $\boldsymbol{p}$ & B & SE & $\begin{array}{l}\text { t } \\
\text { value }\end{array}$ & $\boldsymbol{p}$ & B & SE \\
\hline $\begin{array}{l}\text { Tracking } \\
\text { development }\end{array}$ & & & & & & & & & & \\
\hline & & & & & & & & & & & \\
\hline
\end{tabular}




\begin{tabular}{|c|c|c|c|c|c|c|c|c|c|c|}
\hline Intercept & 4.31 & 0.03 & 165.79 & 0.001 & 4.23 & 0.03 & 151.74 & 0.001 & 4.42 & $0 . C$ \\
\hline \multicolumn{11}{|l|}{$\operatorname{Pre}(\mathrm{ref})^{\mathrm{a}}$} \\
\hline Post & 0.12 & 0.03 & 4.32 & $\begin{array}{l}< \\
0.001\end{array}$ & 0.18 & 0.03 & 5.91 & $\begin{array}{l}< \\
0.001\end{array}$ & $0.04^{b}$ & $0 . C$ \\
\hline \multicolumn{11}{|l|}{$\begin{array}{l}\text { Recognizing } \\
\text { when } \\
\text { development } \\
\text { does not } \\
\text { match age } \\
\text { norm }\end{array}$} \\
\hline Intercept & 4.29 & 0.03 & 161.91 & $\begin{array}{l}< \\
0.001\end{array}$ & 4.24 & 0.03 & 149.18 & $\begin{array}{l}< \\
0.001\end{array}$ & 4.42 & $0 . C$ \\
\hline \multicolumn{11}{|l|}{ Pre (ref) } \\
\hline Post & 0.11 & 0.03 & 3.74 & $\begin{array}{l}< \\
0.001\end{array}$ & 0.18 & 0.03 & 5.97 & $\begin{array}{l}< \\
0.001\end{array}$ & 0.06 & $0 . C$ \\
\hline \multicolumn{11}{|l|}{$\begin{array}{l}\text { Talking with } \\
\text { parents } \\
\text { about } \\
\text { development }\end{array}$} \\
\hline Intercept & 4.31 & 0.03 & 144.48 & $\begin{array}{l}< \\
0.001\end{array}$ & 4.27 & 0.03 & 140.95 & $\begin{array}{l}< \\
0.001\end{array}$ & 4.44 & $0 . C$ \\
\hline \multicolumn{11}{|l|}{ Pre (ref) } \\
\hline Post & 0.10 & 0.03 & 3.70 & $\begin{array}{l}< \\
0.001\end{array}$ & 0.14 & 0.03 & 4.85 & $\begin{array}{l}< \\
0.001\end{array}$ & 0.04 & $0 . C$ \\
\hline \multicolumn{11}{|l|}{$\begin{array}{l}\text { Talking with } \\
\text { parents } \\
\text { when } \\
\text { concerned }\end{array}$} \\
\hline Intercept & 4.31 & 0.03 & 156.17 & $\begin{array}{l}< \\
0.001\end{array}$ & 4.14 & 0.05 & 85.64 & $\begin{array}{l}< \\
0.001\end{array}$ & 4.46 & $0 . C$ \\
\hline \multicolumn{11}{|l|}{ Pre (ref) } \\
\hline Post & 0.12 & 0.03 & 4.44 & $\begin{array}{l}< \\
0.001\end{array}$ & 0.15 & 0.03 & 5.67 & $\begin{array}{l}< \\
0.001\end{array}$ & 0.05 & $0 . C$ \\
\hline $\begin{array}{l}\text { Making } \\
\text { referrals }\end{array}$ & & & & & & & & & & \\
\hline
\end{tabular}




\begin{tabular}{|c|c|c|c|c|c|c|c|c|c|}
\hline Intercept & 4.22 & 0.03 & 129.88 & $\begin{array}{l}< \\
0.001\end{array}$ & 4.17 & 0.03 & 123.10 & $\begin{array}{l}< \\
0.001\end{array}$ & 4.43 \\
\hline Pre (ref) & & & & & & & & & \\
\hline Post & 0.19 & 0.03 & 6.36 & $\begin{array}{l}< \\
0.001\end{array}$ & 0.23 & 0.04 & 6.25 & $\begin{array}{l}< \\
0.001\end{array}$ & 0.06 \\
\hline
\end{tabular}

Poisson analysis used unless otherwise specified

${ }^{a}$ Reference group

${ }^{\mathrm{b}}$ Quasi-Poisson mixed model used

Recognizing when development does not match age norm. There was a statistically significant ${ }^{2}$ pre-post increase in perceived knowledge (pre $=76 ;$ post $=90 ; \beta=$ $0.11, t[120]=3.74, p<0.001)$, access to tools ( $\mathrm{pre}=73$; post $=89 ; \beta=0.18, t[120]$ $=5.97, \mathrm{p}<0.001)$, and priority $(\mathrm{pre}=88 ; \mathrm{post}=95 ; \beta=0.06, t[120]=3.47, p=$ 0.001) (Fig. 2; Table 3).

Talking with parents about development. There was a statistically significant ${ }^{3}$ pre- $^{-}$ post increase in perceived knowledge ( $\mathrm{pre}=81$; post $=91 ; \beta=0.10, t[114]=3.70$, $p<0.001)$ and access to tools (pre $=75 ;$ post $=90 ; \beta=0.14, t[114]=4.85, p<$ 0.001 ), but not priority (see Fig. 3 and Table 3).

Talking with parents when concerned. There was a statistically significant ${ }^{2}$ prepost increase in perceived knowledge (pre $=79$; post $=91 ; \beta=0.12, t[118]=4.44$, $p<0.001$ ), access to tools ( $\mathrm{pre}=75$; post $=96 ; \beta=0.15, t[118]=5.67, p<0.001$ ), and priority (pre $=79$; post $=91 ; \beta=0.05, t[118]=2.94, p=0.001)$ (Fig. 4; Table $3)$.

Making referrals. There was a statistically significant ${ }^{2}$ pre-post increases for perceived knowledge ( pre $=71.5$; post $=91 ; \beta=0.19, t[115]=6.36, p<0.001$ ), access to tools ( $\mathrm{pre}=66.5$; post $=92 ; \beta=0.23, t[115]=6.25, \mathrm{p}<0.001$ ), and priority (pre $=91$; post $=96 ; \beta=0.06, t[115]=3.28, p=0.001)($ Fig. 5; Table 3$)$.

Demonstrated knowledge of referral to Dr. or Part C/Part B (binary). For binary referral data, four outcomes were created: demonstrated knowledge of referral to 
Part C/Part B, demonstrated knowledge of referral to Dr., demonstrated knowledge of referral to either Dr. or Part C/Part B, and demonstrated knowledge of referral to both Dr. and Part C/Part B. There was a statistically significant ${ }^{4}$ pre-post increases for referral to Dr. or Part C/Part B (pre $=66 \%$; post $=80 \% ; O R=3.10$ [95\% CI 1.87-5.15], $t[126]=4.38, p<0.001)$, referral to Dr. and Part C/Part B $($ pre $=29 \% ;$ post $=41 \% ; O R=2.57[95 \%$ CI 1.57-4.22], $t[126]=3.37, p<0.001)$, and referral to Dr. only (pre $=39 \%$; post $=63 \% ; O R=4.74$ [95\% CI 2.88-7.82], $t[124]=6.11, \mathrm{p}<0.001)$, but not referral to Part C/Part B only (pre $=56 \%$; post $=$ $58 \% ; O R=1.21[95 \%$ CI 0.74-1.96], $t[124]=0.76, \mathrm{p}=0.45)$ (Fig. 6; Table 4).

\section{Table 4}

Watch Me! pre-post changes in key binary outcome variables

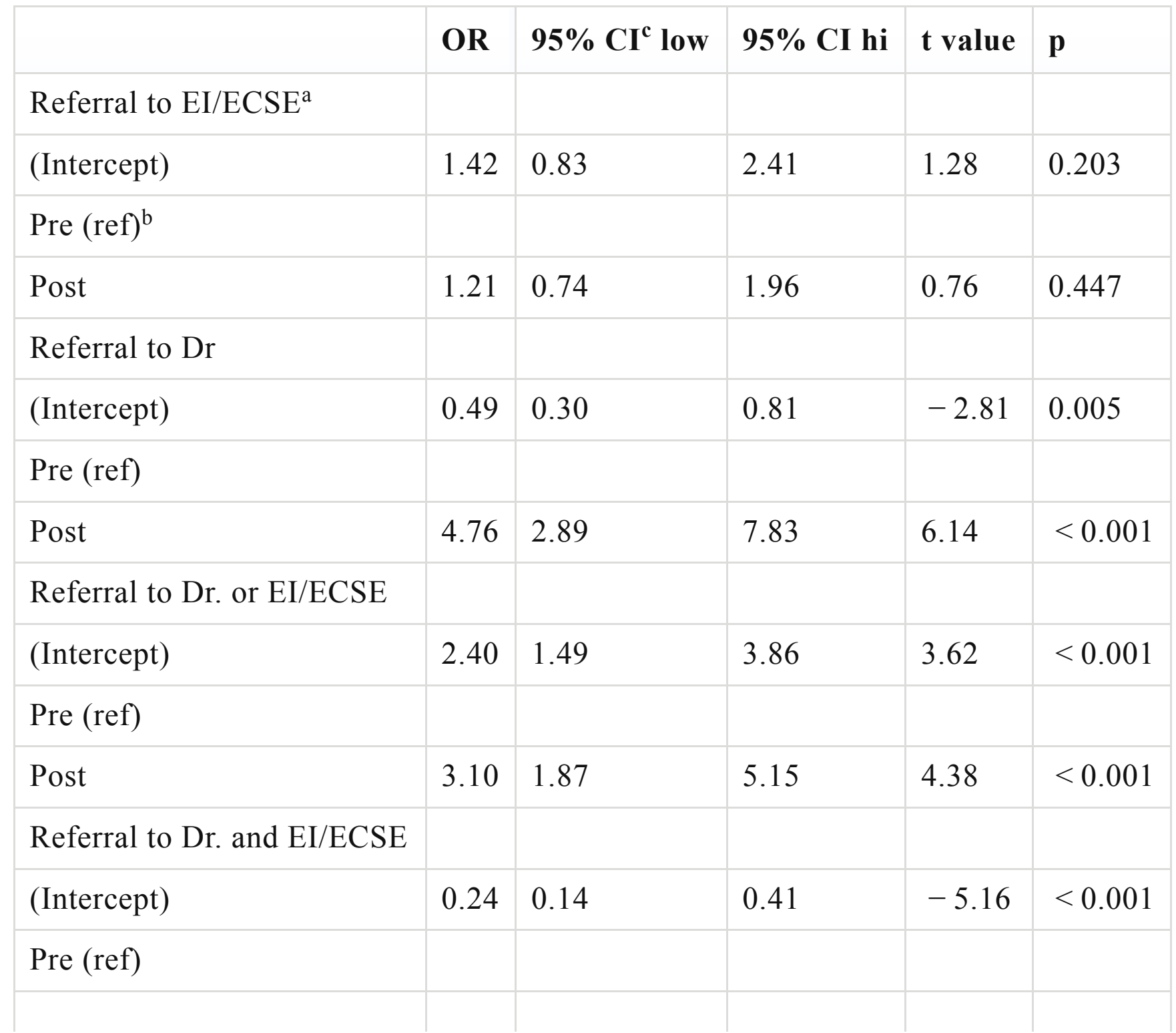


Post

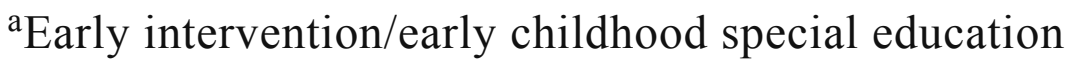

${ }^{b}$ Reference group

${ }^{\mathrm{c} C o n f i d e n c e ~ i n t e r v a l ~}$

Attitude that tracking developmental milestones with an objective checklist is important (binary). There were proportional increases in childcare providers indicating the belief that is important to track developmental milestones with an objective checklist (pre $=92 \%$; post $=100 \%$ ); however, sparse cell counts prevented follow-up analyses (Fig. 6; Table 4).

\section{Conclusions for Practice}

This program evaluation study assessed the impact of "Watch Me!" training on childcare providers' knowledge and attitudes about developmental monitoring for the purposes of identifying and referring when there is a concern about a child's development. Among the group of childcare providers studied, the "Watch Me!" training had a significant immediate impact on childcare providers' perception that they had the knowledge and could access tools needed to carry out five components of developmental monitoring: tracking development; recognizing developmental delays; talking to parents about development; talking to parents about developmental concerns; and making referrals when there was a concern about a child's development (Figs. 1, 2, 3, 4, 5). Median pre-post increases were greatest for perceived access to tools for talking to parents when there is a concern and for perceived knowledge and access to tools related to recognizing when development is not typical and making referrals (Figs. 2 and 3).

Although there was a significant pre-post increase in perceived knowledge and access to tools for making referrals, childcare providers' perception that they are knowledgeable about referrals does not necessarily translate to being able to demonstrate knowledge of recommended referrals (Chödrön et al. 2019). Recommended referrals when there is a concern include both the child's doctor and the Part C or Part B services (depending on the child's age). In this study, the 
"Watch Me!" training only improved knowledge of referring to the doctor $(39 \%$ pre to $63 \%$ post), but not Part C/Part B (56\% pre to 58\% post; Fig. 6). While posttraining knowledge of referral to the doctor exceeded post-training knowledge of referral to Part C/Part B services (63\% and 58\% respectively), for all practical purposes the post-training knowledge levels reflect knowledge of referral to the doctor catching up to the pre-training knowledge of referral to Part C/Part B services.

"Watch Me!" training also had a significant immediate impact on several attitudes related to developmental monitoring. Specifically, training significantly impacted the attitude that it is a priority both to recognize when a child's development is not typical and to make referrals when the provider or parent has a concern about a child's development (Figs. 2 and 5). Median pre-post increases in priority was highest for recognizing when a child's development is not typical, which was also the lowest priority variable at baseline (Fig. 2). Overall, rating of priority for all other variables was high at baseline, creating a ceiling effect (Figs. 1 and 3). There was also a proportional increase in attitude that it is important to track development using an objective checklist (Fig. 6), and while it was not possible to test this change statistically, it is notable that all respondents at post indicated it was important to use an objective checklist.

Ongoing studies indicate that increasing developmental screening and monitoring among health care providers is a very challenging task, and most recent estimates indicate that only about a third of children 9-35 months of age receive screening and $37 \%$ receive monitoring (Hirai et al. 2018). Considering this challenge, a reasonable solution is to recruit other professionals engaged in the work of supporting healthy development, such as childcare providers. Collectively, the data reported here indicate that "Watch Me!" training holds promise as an instructional tool to increase knowledge and change attitudes to prepare childcare providers to conduct developmental monitoring and make referrals when there is a concern about a child's development. Thus, if done well, childcare providers may be trained to aid in the identification of children who would benefit from early intervention and treatment that may not receive ongoing developmental surveillance from their health care providers. 


\section{Limitations and Future Directions}

One limitation of the present study is the small sample. Future research could utilize a larger sample to confirm post-training outcomes, and to assess whether those outcomes are sustained over time. A notable limitation of the present study is that, despite a good post-test response rate, responses to follow up surveys 39 months after the study were quite low, preventing a more in-depth analysis of the long-term effects of "Watch Me!" training Reference also added to reference list. (Chödrön et al. 2017) (BLINDED REFERENCE). In early childhood professional development that didactic, or what is commonly referred to as "sit and get," instruction is generally understood to be insufficient to drive change in professional practice (La Paro and King 2019).

This study was also limited in the range of outcomes that were measured. To ascertain how developmental monitoring using LTSAE resources impacts early detection and access to early intervention, further studies should measure outcomes including identification of concerns, referrals made, parent follow-up on referrals, and enrollment in Part C/Part B services and access to health care services. Assessing these outcomes will require an implementation study of sufficient duration to allow time not only for training and implementation of developmental monitoring but also for referrals to result in follow-up.

Further studies are needed using an implementation science approach (Cook and Odom 2013; Interagency Autism Coordinating Committee 2017) in order to fully understand the impact of training and developmental monitoring practice in childcare and other early childhood settings. Given the complexity of child assessment in childcare settings, particular attention should be given to whether developmental monitoring with LTSAE is applied for purposes for which it was designed. The current study is not able to address whether "Watch Me!" training has a greater or lesser impact than other trainings. In future research, a randomized control trial design would enable the impact of "Watch Me!" training to be compared to alternate training. Finally, implementation of developmental monitoring alone should be compared to implementation of developmental screening alone, developmental screening together with developmental monitoring, 
and identification practice as normal (i.e., without additional monitoring or screening training and resources) to ascertain which early identification strategies offer the most promise for feasible and effective identification of children at risk for developmental disability in childcare settings.

AQ1

Publisher's Note

Springer Nature remains neutral with regard to jurisdictional claims in published maps and institutional affiliations.

\section{Acknowledgements}

We would like to thank the participating childcare providers and programs for their contributions to the study. This evaluation study was supported by funding from the Disability Research and Dissemination Center (DRDC) through its cooperative agreement number 5U01DD001007 from the Centers for Disease Control (CDC) and Prevention and by the Clinical and Translational Science Award (CTSA) program. Data analysis was supported in part through the NIH National Center for Advancing Translational Sciences (NCATS), Grant UL1TR000427. The contents of this report are solely the responsibility of the authors and do not necessarily represent the official views of the DRDC, the CDC, or the NIH.

\section{Electronic supplementary material}

Below is the link to the electronic supplementary material.

(DOCX $39 \mathrm{~kb})$

\section{References}

About Bright Futures. (n.d.). Retrieved from https://brightfutures.aap.org/about/Pages/About.aspx.

Bartlett, M., \& Mickelson, A. (2019). The changing landscape of education for 
young children receiving early intervention and early childhood special education. In C. P. Brown, M. B. McMullen, \& N. File (Eds.), The Wiley handbook of early childhood care and education (pp. 239-258). Hoboken, NJ: Wiley.

Boh, A., \& Johnson, L. D. (2018). Universal screening to promote early identification of developmental delays: Exploring childcare providers beliefs and practices. Early Child Development and Care, 188(12), 1694-1708.

Boyle, C. A., Boulet, S., Schieve, L. A., Cohen, R. A., Blumberg, S. J., Yeargin-Allsopp, M., \& Kogan, M. D. (2011). Trends ***in the prevalence of developmental disabilities in US children, 1997-2008. Pediatrics, 127(6), 1034-1042.

Bradshaw, J., Steiner, A. M., Gengoux, G., \& Koegel, L. K. (2015). Feasibility and effectiveness of very early intervention for infants at-risk for autism spectrum disorder: A systematic review. Journal of Autism and Developmental Disorders, 45(3), 778-794.

Branson, D., \& Bingham, A. (2017). Child care providers' competence and confidence in referring children at risk for developmental delays. Infants \& Young Children, 30, 41-57.

Branson, D., Vigil, D. C., \& Bingham, A. (2008). Community childcare providers' role in the early detection of autism spectrum disorders. Early Childhood Education Journal, 35(6), 523-530.

Bricker, D., Macy, M., Squires, J., \& Marks, K. (2013). Developmental screening in your community. Baltimore, MD: Paul H. Brookes.

Burt, J. D. (2013). An evaluation of the milestone moments booklet and interactive milestone checklist with child care providers. Omaha, NE: Munroe Meyer Institute at the University of Nebraska Medical Center. 
Chödrön, G., Pizur-Barnekow, K., Viehweg, S., Puk-Ament, A., \& Barger, B. (2019). Childcare providers' attitudes, knowledge, and practice related to developmental monitoring to promote early identification and referral. Early Child Development and Care. https://doi.org/10.1080/03004430.2019.1626373.

Cook, B. G., \& Odom, S. L. (2013). Evidence-based practices and implementation science in special education. Exceptional Children, 79(2), 135144.

Council on Children with Disabilities. (2006). Identifying infants and young children with developmental disorders in the medical home: An algorithm for developmental surveillance and screening. Pediatrics, 118(1), 405-420.

Developmental Monitoring and Screening. (2020). Retrieved February 6, 2020 from https://www.cdc.gov/ncbddd/childdevelopment/screening.html.

Early Childhood Technical Assistance Center. (2017). Part C Infant and Toddler Program Federal Appropriations and National Child Count 1987-2016. Retrieved July 1, 2017 from http://ectacenter.org/partc/partcdata.asp.

Graybill, E., Self-Brown, S., Lai, B., Vinoski, E., McGill, T., \& Crimmins, D. (2016). Addressing disparities in parent education: Examining the effects of Learn the Signs/Act Early parent education materials on parent outcomes. Early Childhood Education Journal, 44(1), 31-38.

Hagan, J. F., Shaw, J. S., \& Duncan, P. M. (2017). Bright futures: Guidelines for health supervision of infants, children, and adolescents (4th ed.). Elk Grove Village, IL: American Academy of Pediatrics.

Hirai, A. H., Kogan, M. D., Kandasamy, V., Reuland, C., \& Bethell, C. (2018). Prevalence and variation of developmental screening and surveillance in early childhood. JAMA: Journal of the American Medical Association, 172(9), 857866. 
Interagency Autism Coordinating Committee. (October 2017). 2016-2017 Interagency Autism Coordinating Committee Strategies Plan for Autism Spectrum Disorder. Retrieved from the U.S. Department of Health and Human Services Interagency Autism Coordinating Committee website: https://iacc.hhs.gov/publications/strategic-plan/2017/.

Landa, R. J., \& Kalb, L. G. (2012). Long-term outcomes of toddlers with autism spectrum disorders exposed to short-term intervention. Pediatrics, 130(Supplement 2), S186-S190.

La Paro, K., \& King, E. (2019). Professional development in early childhood education. In C. P. Brown, M. B. McMullen, \& N. File (Eds.), The Wiley handbook of early childhood care and education (pp. 427-448). Hoboken, NJ: Wiley.

Macy, M., Marks, K., \& Towle, A. (2014). Missed, misused, or mismanaged: Improving early detection systems to optimize child outcomes. Topics in Early Childhood Special Education, 34(2), 94-105.

National Association for the Education of Young Children. (2018). NAEYC early learning program accreditation standards and assessment items.

Washington, DC: NAEYC. Retrieved from https://www.naeyc.org/sites/default/files/globallyshared/downloads/PDFs/accreditation/earlylearning/standards_and_assessment_web_0.pdf.

National Association for the Education of Young Children. (2009). NAEYC standards for early childhood professional preparation: A position statement of the National Association for the Education of Young Children. Washington, DC: National Association for the Education of Young Children. Retrieved from https://www.naeyc.org/resources/position-statements/standards-professionalpreparation.

Pinheiro, J., Bates, D., DebRoy, S., Sarkar, D., Heisterkamp, S., Van Willigen, 
B., \& Maintainer, R. (2018). Package 'nlme'. Retrieved from:

http://ftp5.gwdg.de/pub/misc/cran/web/packages/nlme/nlme.pdf

Pizur-Barnekow, K., Erickson, S., Johnston, M., Bass, T., Lucinski, L., \& Bleuel, D. (2010). Early identification of developmental delays through surveillance, screening, and diagnostic evaluation. Infants \& Young Children, 23(4), 323-330.

Raspa, M., Levis, D. M., Kish-Doto, J., Wallace, I., Rice, C., Barger, B., \& Wolf, R. B. (2015). Examining ***parents' experiences and information needs regarding early identification of developmental delays: Qualitative research to inform a public health campaign. Journal of Developmental \& Behavioral Pediatrics, 36(8), 575-585.

Revelle, W., \& Revelle, M. W. (2015). Package 'psych'. The Comprehensive $R$ Archive Network. Retrieved from: http://www.test.personalityproject.org/r/psych/psych-manual.pdf

Ripley, B., Venables, B., Bates, D. M., Hornik, K., Gebhardt, A., Firth, D., \& Ripley, M. B. (2013). Package 'mass'. Cran R. Retrieved from: https://cran.revolutionanalytics.com/web/packages/MASS/MASS.pdf

Rogers, S. J., Estes, A., Lord, C., Vismara, L., Winter, J., Fitzpatrick, A., \& Dawson, G. (2012). Effects of ***a brief Early Start Denver Model (ESDM)based parent intervention on toddlers at risk for autism spectrum disorders: A randomized controlled trial. Journal of the American Academy of Child \& Adolescent Psychiatry, 51(10), 1052-1065.

Rogers, S. J., Estes, A., Lord, C., Munson, J., Rocha, M., Winter, J., \& Talbott, M. (2019). A multisite ***randomized controlled two-phase trial of the Early Start Denver Model compared to treatment as usual. Journal of the American Academy of Child \& Adolescent Psychiatry. https://doi.org/10.1016/j.jaac.2019.01.004. 
Rosenberg, S. A., Zhang, D., \& Robinson, C. C. (2008). Prevalence of developmental delays and participation in early intervention services for young children. Pediatrics, 121(6), e1503-e1509.

U.S. Department of Health and Human Services \& U.S. Department of Education. (2014). Birth to 5: Watch me Thrive!: An early care and education provider's guide for developmental and behavioural screening. Washington, DC: U.S. Department of Health and Human Services \& U.S. Department of Education.

Chödrön, G., Ershler, J., Pizur-Barnekow, K., Viehweg, S., Barger, B., \& PukAment, A. (2017). Evaluation of developmental monitoring using 'learn the Signs. Act early.' in childcare settings. Madison, WI: Waisman Center University Center for Excellence in Developmental Disabilities.

Diane Branson, Debra C. Vigil, Ann Bingham, (2008) Community Childcare Providers' Role in the Early Detection of Autism Spectrum Disorders. Early Childhood Education Journal 35 (6):523-530

Centers for Disease Control and Prevention. (1999). Framework for program evaluation in public health. MMWR. 48(No. RR-11):1-40.

J. P. Guevara, M. Gerdes, R. Localio, Y. V. Huang, J. Pinto-Martin, C. S. Minkovitz, D. Hsu, L. Kyriakou, S. Baglivo, J. Kavanagh, S. Pati, (2013) Effectiveness of Developmental Screening in an Urban Setting. PEDIATRICS $131(1): 30-37$

${ }^{1}$ In the cited study, developmental disability is defined as including "attention deficit hyperactivity disorder; intellectual disability; cerebral palsy; autism; seizures; stuttering or stammering; moderate to profound hearing loss; blindness; learning disorders; and/or other developmental delays" (p. 1034).

2 GLM Poisson analysis was used.

3 GLM analysis was used. 
${ }^{4}$ GLM logistic regression analyses were used. 